BMJ Paediatrics Open

\title{
Sleep problems, behavioural problems and respiratory health in children born extremely preterm: a parental questionnaire study
}

Kristine Marie Stangenes, ${ }^{\odot, 2}$ Mari Hysing, ${ }^{3}$ Irene Bircow Elgen, ${ }^{4,5}$ Thomas Halvorsen, ${ }^{2}$ Trond Markestad, ${ }^{2}$ Bjørn Bjorvatn ${ }^{6,7}$

To cite: Stangenes KM, Hysing M, Elgen IB, et al. Sleep problems, behavioural problems and respiratory health in children born extremely preterm: a parental questionnaire study. BMJ Paediatrics Open 2019;3:e000534. doi:10.1136/ bmjpo-2019-000534

Received 3 June 2019 Revised 15 August 2019 Accepted 17 August 2019
Check for updates

\section{(C) Author(s) (or their} employer(s)) 2019. Re-use permitted under CC BY-NC. No commercial re-use. See rights and permissions. Published by BMJ.

For numbered affiliations see end of article.

Correspondence to Dr Kristine Marie Stangenes; kristine.stangenes@gmail.com

\section{ABSTRACT}

Objective To explore whether children born extremely preterm (EPT) with different types of sleep problems had more behavioural and respiratory health problems than EPT children without sleep problems.

Design Prospective, nationwide, questionnaire-based study. At 11 years of age, parents reported on four current sleep problems: difficulty falling asleep or frequent awakenings, snoring, daytime sleepiness and not recommended sleep duration (<9hours). Behavioural problems were assessed by parents and teachers with the Strengths and Difficulties Questionnaire (SDQ). Parents assessed respiratory symptoms with the International Study of Asthma and Allergies in Childhood questionnaire and described use of asthma medication.

Setting Norway.

Patients EPT children.

Main outcome measures Specified sleep problems, behavioural problems and respiratory health.

Results Data were obtained from 216 of $372(58 \%)$ of eligible children. All four specified sleep problems were associated with significantly higher parent-reported SDQ total-score (OR 1.1 for all), and except for not recommended sleep duration, also with higher teacher-reported SDQ total-score (OR 1.1 for all). Daytime sleepiness was strongly associated with wheezing last 12 months (OR 3.4), disturbed sleep due to wheezing (OR 3.9), wheeze during or after exercise (OR 2.9), use of inhaled corticosteroids or oral leukotriene modifiers (OR 3.4) and use of bronchodilators (OR 3.9). Snoring was associated with wheezing during or after exercise (OR 2.8) and current asthma (OR 4.2).

Conclusion EPT children with different types of sleep problems had more behavioural and respiratory health problems than EPT children without sleep problems.

\section{INTRODUCTION}

Sleep is critical for development, maturation and health on the journey from infancy to adulthood. ${ }^{1}$ Sleep problems in children have been associated with asthma and other respiratory symptoms, ${ }^{2}$ and with mental health problems, such as conduct problems, hyperactivity and emotional problems. ${ }^{3-5}$ Children with neurological disabilities often have sleep problems, ${ }^{6}$ but somatic and mental

\section{What is known about the subject?}

School-aged extremely preterm (EPT) children are at increased risk of sleep problems, behavioural problems and respiratory symptoms.

- Whether sleep problems are associated with behavioural problems and respiratory symptoms in school-aged EPT children, have not been explored previously.

\section{What this study adds?}

- Sleep disturbances in EPT children were strongly linked to behavioural problems and to respiratory symptoms.

- The study suggests that sleep disturbances may be an overlooked area of concern in EPT children.

comorbidities may contribute to these problems. $^{7-9}$

We have previously shown that children born extremely preterm (EPT) have more sleep problems throughout childhood than children born at term, and that the prevalence increases with the degree of neurodevelopmental disability. ${ }^{10}$ Children born EPT are also at increased risk of behavioural problems and respiratory morbidities, ${ }^{11} 12$ but we do not know how such difficulties affect their sleep.

We hypothesised that sleep problems at 11 years in children born EPT are associated with behavioural problems and respiratory symptoms and aimed to explore the significance of these relationships by addressing four specified sleep problems: difficulty falling asleep or frequent awakenings, snoring, daytime sleepiness and insufficient sleep duration. 


\section{METHODS}

\section{Population}

The study population was a national cohort of all children born EPT ( $\mathrm{n}=372)$ in Norway during 1999-2000. EPT was defined as gestational age $(\mathrm{GA})<28$ completed weeks or birth weight $(\mathrm{BW})<1000 \mathrm{~g}$. The children were prospectively followed from birth and assessed at 2, 5 and 11 years of age. Method for determination of GA and overall outcome in terms of mortality and morbidities until 11 years have been published previously. ${ }^{9}{ }^{13-16}$ At 11 years, we obtained information on the families' sociodemographic characteristics and lifestyles, and the children's health, including sleep characteristics, behavioural issues and respiratory health, from postal questionnaires completed by the parents (for behaviour also the children's teacher). EPT children with severe disability were included. (The degree of neurodevelopmental disability was assessed by clinical examination when the children were 5 years old. ${ }^{10}$ )

\section{Sleep problems}

The parents assessed the sleep problems in terms of whether their child had difficulty falling asleep or had frequent awakenings, snored or had daytime sleepiness. The response options to these questions were 'Not true', 'Partly true' and 'Absolutely true'. In our analyses, the responses 'Partly true' and 'Absolutely true' were merged and defined as a sleep problem. Sleep duration was assessed by the following items: at what time their child went to bed and got up on weekdays, how long time it took from going to bed until falling asleep (sleep onset latency) and how long the child was awake during the night after sleep onset. We calculated total sleep duration as the time in bed minus sleep onset latency and time awake after sleep onset. In accordance with recently published guidelines, recommended sleep duration at 11 years was defined as $9-11$ hours. ${ }^{17}$ The same sleep variables have been used in a previous paper. ${ }^{18}$

\section{Behavioural problems}

Parents and teachers completed the Strengths and Difficulties Questionnaire (SDQ). SDQ is a general behavioural screening questionnaire for 4-17-year-old children and has good psychometric properties also for children born preterm. ${ }^{19} 20$ It contains five items in each of four subscales: emotional problems, hyperactivity/inattention, conduct problems and peer problems. Each item is scored on a three-point scale; 'Not true' $(0)$, 'Somewhat true" and 'Certainly true'. ${ }^{2}$ The total subscale score ranges from 0 to 10 and the total score from 0 to 40 .

\section{Respiratory health}

The parents completed the International Study of Asthma and Allergies in Childhood (ISAAC) questionnaire ${ }^{21}$ which contains the following questions on respiratory symptoms during the last 12 months: did your child experience wheezing or whistling in the chest and, if so, how many attacks; how often was the child's sleep disturbed due to wheezing; was wheezing ever so severe that the child had trouble saying more than one or two words at a time between breaths; did the child's chest sounded wheezy during or after exercise; and did the child have a dry cough at night, apart from cough associated with a cold or chest infection.

We also asked for current use of asthma medications, including inhaled corticosteroids, short or long acting $\beta_{2}$-agonists and oral leukotriene modifiers, and whether the child had ever been diagnosed with asthma. Current asthma was defined as yes to 'ever asthma' combined with either respiratory symptoms or use of asthma medication during the previous 12 months, or asthma medication and symptoms during the past 12 months regardless of reporting asthma.

\section{Statistical analyses}

For each specific dichotomised sleep outcome variable, the groups were compared according to the results on the SDQ ISAAC, current asthma versus no asthma, use versus no use of inhaled corticosteroids or oral leukotriene modifiers, and use versus no use of inhaled bronchodilators.

Group comparisons were performed using Student's t-tests, $\chi^{2}$ tests or Fisher's exact tests. ORs and 95\% CIs were calculated after adjusting for sex, single parenthood and maternal education (dichotomised as a 3-year college education or not) in logistic regression analyses. Significance level was set at $\alpha$-level 0.05 . We also performed subanalyses where we included small for gestational age (SGA) as a covariate. This was done for the SDQ and for the questions about respiratory health. SGA was defined as a $\mathrm{BW}$ below the 10 th percentile. ${ }^{22}$ For the questions about respiratory health, subanalyses were also made in which information about current smoking among parents (mother or father) was included as a covariate

\section{Patient and public involvement}

Patient representatives were involved in this national follow-up study.

\section{RESULTS}

Sleep and ISAAC data were obtained for 216/372 (58\%) children. SDQ was completed by the parents for 215 and by the teachers for 184 of them. Difficulty falling asleep or frequent awakenings was reported for $27.3 \%$, snoring for $28.0 \%$, daytime sleepiness for $17.1 \%$ and sleep duration less than the recommended 9 hours for $24.1 \%$ of the children. None of the children slept more than recommended. There were no significant sex differences regarding the prevalence of the specified sleep problems. The average total SDQ score was 8.8 and the prevalence of current asthma was $18 \%$. Of the 216 participating children, six had severe disability at age 5 years. Parent and child characteristics are described in table 1. Participants and non-participants did not differ regarding GA or the ratio of SGA, bronchopulmonary dysplasia or 
Table 1 Characteristics of the 216 of 372 eligible children who were born extremely preterm* in Norway in 1999-2000 and participated in the follow-up at 11 years of age

\begin{tabular}{ll}
\hline Family background & $\%(\mathbf{n})$ \\
\hline Single parent & $8.8(19)$ \\
\hline Higher education mother† & $68.8(148)$ \\
\hline Higher education father† & $45.1(96)$ \\
\hline Demographic characteristics & Mean (range) \\
\hline Gestational age, weeks & $26.6(23.0-32.0)$ \\
\hline Birth weight, grams & $869(450-1370)$ \\
\hline Small for gestational age & $\%(n)$ \\
\hline Boy & $18.1(39)$ \\
\hline $\begin{array}{l}\text { Severe disability§ (based on clinical } \\
\text { examination at 5 years) }\end{array}$ & $3.3(6)$ \\
Current smoking, mother or father & $35.2(76)$ \\
\hline
\end{tabular}

${ }^{*}$ Gestational age $<28$ weeks or birth weight $<1000 \mathrm{~g}$

†College or university education when the child was 11 years old. $\ddagger$ Small for gestational age: birth weights $<10$ th percentile. ${ }^{22}$

$\S$ Severe disability defined as one or more of the following: cerebral palsy class 4-5 on the Gross Motor Function Classification System for Cerebral Palsy, Full intelligence quotient (IQ) score more than $3 S D$ s below the reference mean value of 100 , legal blindness, or complete deafness. ${ }^{10}$

retinopathy of prematurity, but there was a tendency for less severe disability among the participants $(3.3 \% \quad(n=6)$ vs $9.8 \%(\mathrm{n}=12))$.

\section{Sleep problems and behavioural problems}

The children who had difficulty falling asleep or frequent awakenings had a higher parent-reported SDQ totalscore, and they had higher scores on all four subscales compared with the children who did not have this sleep problem. They also had a higher teacher-reported SDQ total-score and a higher teacher-reported emotional problems score (table 2). The children who snored had a higher parent-reported and teacher-reported SDQ totalscore and a higher score on conduct problems than the children who did not snore. The children who snored had also more emotional problems (see table 2 for details).

The children with daytime sleepiness had a higher parent-reported and teacher-reported SDQ total-score and a higher score on emotional problems than children without daytime sleepiness. The parents also reported that these children also had more hyperactivity/inattention problems and peer problems. The children who had a sleep duration of less than the recommended 9 hours, had a higher parent-reported SDQ total-score than the children who slept longer (table 2). The association between the specified sleep problems and the respective SDQ scores remained unchanged after including SGA $(n=60)$ as a covariate in the adjusted analysis, except for the association between snoring and teacher-reported conduct problems which became non-significant (data not shown).

\section{Sleep problems and respiratory health}

The children who had difficulty falling asleep or frequent awakenings more often had wheezing during the last 12 months, but the association did not remain significant after adjustment (table 3). Only two children had problems with speaking due to wheezing. This question was therefore not included in the further analyses.

Snoring was associated with wheezing during or after exercise, current asthma and use of bronchodilators (table 3). Daytime sleepiness was associated with wheezing during the last 12 months, disturbed sleep due to wheezing, wheeze during or after exercise, use of inhaled corticosteroids or oral leukotriene modifiers and use of bronchodilators (table 3). Sleep duration less than recommended was associated with disturbed sleep due to wheezing and use of inhaled corticosteroids or oral leukotriene modifiers (table 3 ). The association between these specified sleep problems and the respiratory health problems remained unchanged after including SGA and the parents' current smoking habits (mother or father smoking) as covariates in the adjusted analysis (data not shown).

\section{DISCUSSION}

In this nationwide cohort of EPT children, sleep problems were significantly associated with behavioural and respiratory health problems. Difficulty falling asleep or frequent awakenings, snoring and daytime sleepiness were associated with more parent-reported and teacher-reported behavioural problems, whereas sleeping less than recommended was associated with more parent-reported behavioural problems. The sleep problems, and especially daytime sleepiness, were strongly associated with respiratory symptoms, asthma and use of asthma medication.

The average total SDQ scores in our study were higher (total score 8.8) than previously found in unselected Norwegian children (total score 5.4). ${ }^{11}$ The prevalence of current asthma (18\%) was higher than the prevalence of $11 \%$ in an unselected Norwegian cohort of 10-year-old children. ${ }^{23}$ Thus, this EPT cohort had more respiratory, ${ }^{24}$ behavioural ${ }^{11}$ and sleep problems ${ }^{10}$ in mid-childhood than Norwegian children who were not prematurely born, underscoring the overall vulnerability in these children. To what extent such difficulties are interrelated in children born preterm have not been extensively explored.

In a small study of children born at GA less than 32 weeks, Perkinson-Gloor et al found that less restorative sleep was associated with more behavioural problems as reflected in higher SDQ-scores. ${ }^{25}$ However, they did not find more nocturnal awakenings or shorter sleep duration compared with their control group, nor did they find that total sleep time or nocturnal awakenings were associated with SDQ total-scores. Caravale et al studied 2-year-old preterm children (mean GA 31 weeks), and found that they had more frequent sleep difficulties 


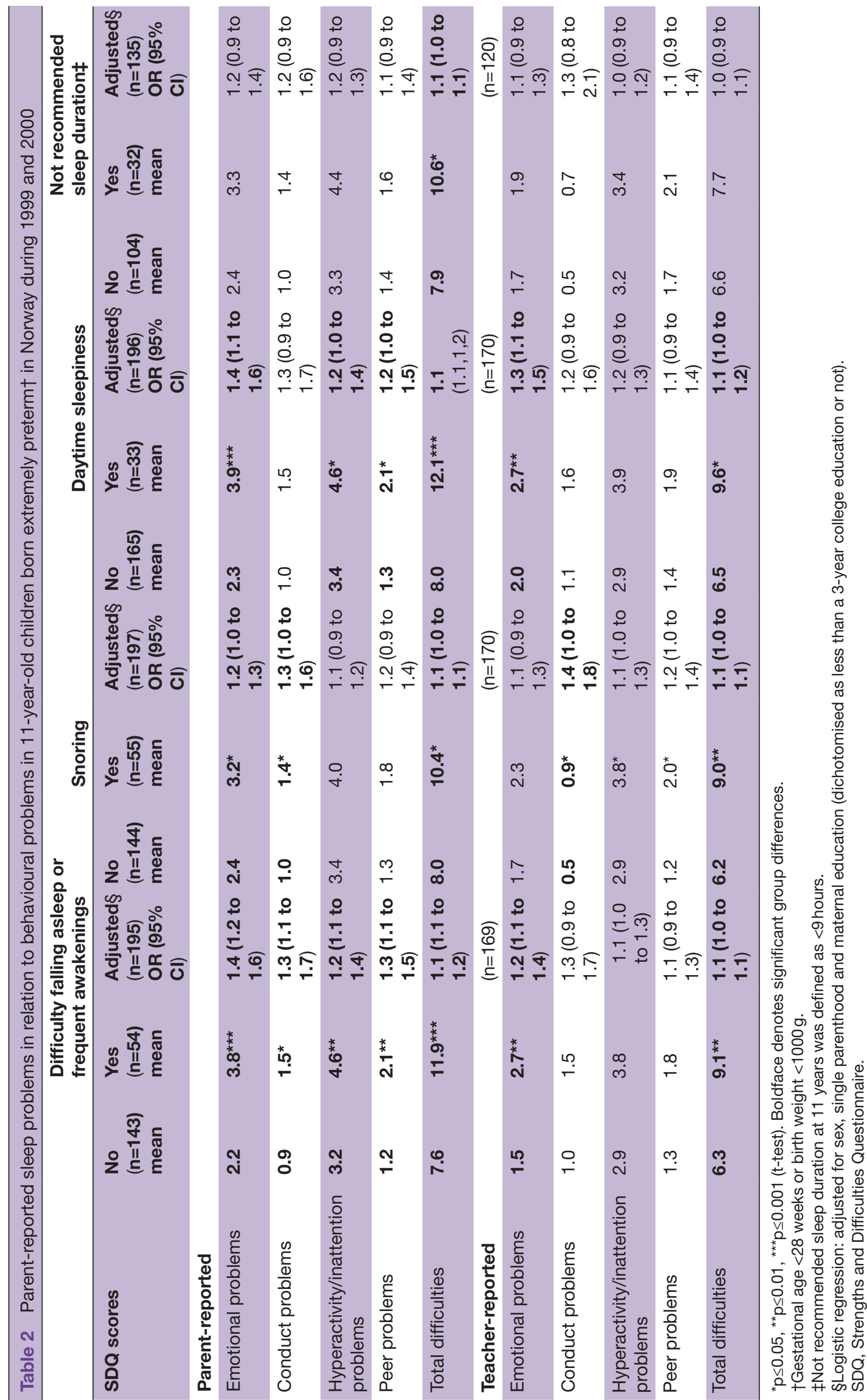




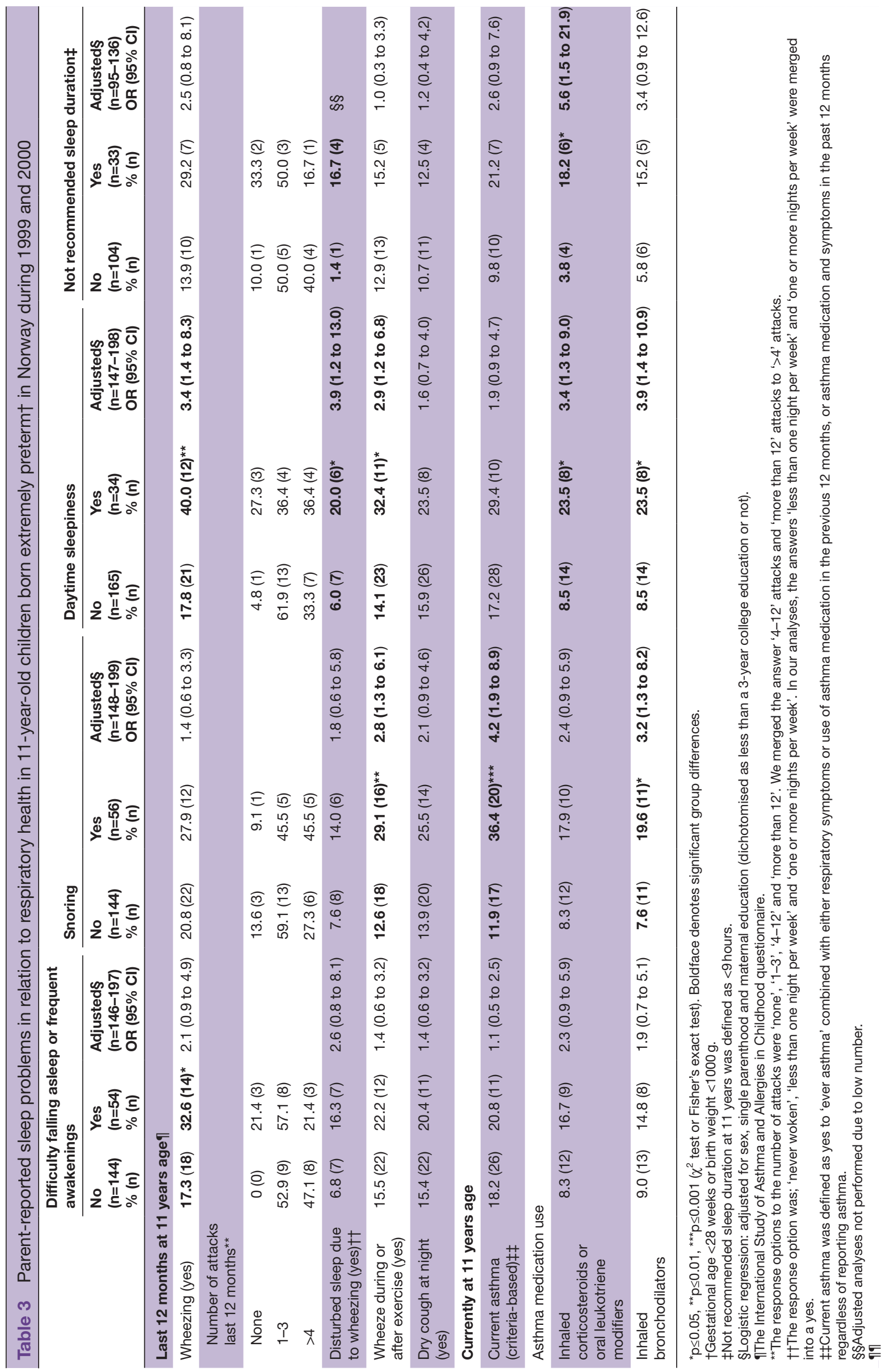


during the night, and that these difficulties were related to problems with emotions and attention, ${ }^{26}$ which is in agreement with our findings. It is worth noting that Perkinson-Gloor et al excluded children with severe developmental delay ${ }^{25}$ and that Caravale et al included only children with normal cognitive, language, and motor development ${ }^{26}$ as opposed to no selections in our study.

Our finding that sleep problems and behavioural problems were associated is in agreement with what has been reported for young children who were not born preterm, ${ }^{27}$ suggesting that studies on sleep and behavioural problems among children in general may be applicable also for children born EPT. Insomnia and restless sleep have been linked to emotional problems, hyperactivity/inattention problems, conduct problems and peer problems as assessed by SDQ. ${ }^{28}$ Moreover, daytime sleepiness was associated with emotional problems, conduct problems and hyperactivity/inattention problems in term born children measured by SDQ of Hestetun $e t a l .^{29}$ These are findings that are in line with our observations in EPT-born children, strengthening the notion that sleep problems are likely to be similarly involved in mental health issues in preterm as well as term-born children.

Snoring in term-born children has also been associated with emotional problems, conduct problems and hyperactivity/inattention problems as assessed by $\mathrm{SDQ}{ }^{30}$ Correspondingly, we found more emotional and conduct problems, but not more hyperactivity/inattention problems among our snoring EPT children. Snoring is a common symptom of sleep disordered breathing (SDB), and previous studies have shown that children born prematurely have an increased risk of SDB. ${ }^{31-35}$ The prevalence SDB during childhood in children born EPT is unknown. In general, SDB in childhood is a risk factor for behavioural problems, externalising symptoms and inattention. More studies are needed to map the association between SDB and behavioural problems in children born EPT.

Our finding that insufficient sleep duration was associated with higher SDQ total-scores is in agreement with findings of an association between short sleep duration and emotional problems, conduct problems and hyperactivity/inattention problems in an unselected cohort of Norwegian children of similar age. ${ }^{36}$

We are unaware of other studies that have addressed relationships between respiratory symptoms and sleep in children born EPT, but our finding that several sleep problems were associated with wheezing and asthma is in agreement with similar findings in children born at term. $^{37-39}$ Although respiratory symptoms in EPT-born children resemble asthma, the pathophysiology of lung disease after preterm birth is different which, for instance, is reflected in that the disease is unresponsive to inhaled corticosteroids. ${ }^{1240-42}$ Their burden of respiratory symptoms may therefore be substantially higher, and more chronic ${ }^{16}$ and therefore more easily overlooked. For example, it is conceivable that poor sleep due to respiratory problems may cause daytime sleepiness and contribute to inattention and learning difficulties which are major challenges for children born EPT. ${ }^{43}{ }^{44}$ Previous studies on term-born children have shown that nocturnal awakening due to asthma is a risk factor for poor school functioning. ${ }^{45}$

The strengths of the present study were the national population-based sample of EPT children, the prospective design, the assessment of behavioural problems by both parents and teachers, and the use of validated instruments for assessing both behavioural problems and respiratory symptoms. The limited response rate at follow-up was a weakness. However, we found that for most variables the assessed children were representative of all survivors at the age of 11 years. We adjusted for single parenthood, maternal education and sex in our analyses, and in subanalyses we also adjusted for SGA and current smoking among parents. We cannot, however, exclude residual confounding. We did not correct for multiple testing, and therefore, the results must be interpreted with caution. Other limitations were lack of detailed information about socioeconomic status, the child's sleep environment, what season the parents answered the questionnaires, and whether the children had been treated for snoring or for sleep problems.

\section{CONCLUSIONS}

In the present study, behavioural problems and respiratory symptoms were strongly associated with sleep disturbances in 11-year-old children born EPT. The associations were similar to what has been found in unselected groups of children. Given the high prevalence of behavioural problems and respiratory symptoms after preterm birth, the study suggests that sleep disturbances may be an overlooked area of concern in preterm born children, and that questions mapping sleep should be included when seeing these children in clinics.

\section{Author affiliations}

${ }^{1}$ Children and Youth Clinic, Haukeland University Hospital, Bergen, Norway

${ }^{2}$ Department of Clinical Science, University of Bergen, Bergen, Norway

${ }^{3}$ Department of Pcychosocial Science, University of Bergen, Bergen, Norway

${ }^{4}$ Department of Clinical Medicine, University of Bergen, Bergen, Norway

${ }^{5}$ Department of Child and Adolescent Psychiatry, Haukeland University Hospital,

Bergen, Norway

${ }^{6}$ Department of Global Public Health and Primary Care, University of Bergen,

Bergen, Norway

${ }^{7}$ Norwegian Competence Center for Sleep Disorders, Haukeland University Hospital, Bergen, Norway

Contributors KMS has conceptualised and designed the study, analysed and interpreted the data, drafted and revised the manuscript critically for important intellectual content and has approved that this version of the manuscript was published. MH, IBE, TH and BB have participated in the concept and design, interpretation of the data and have revised the manuscript and have approved that this version of the manuscript was published. TM has acquired the data, participated in the concept and design, interpretation of the data and has revised the manuscript and has approved that this version of the manuscript was published.

Funding This project was founded by the Norwegian Extra Foundation for Health and Rehabilitation through the Premature Society (2016/F075838). 
Competing interests None declared.

Patient consent for publication Not required.

Ethics approval The study was approved by the Regional Committee on Medical Research Ethics (2009-2271) and the Norwegian Data Inspectorate.

Provenance and peer review Not commissioned; externally peer reviewed.

Data availability statement Data may be obtained from a third party and are not publicly available.

Open access This is an open access article distributed in accordance with the Creative Commons Attribution Non Commercial (CC BY-NC 4.0) license, which permits others to distribute, remix, adapt, build upon this work non-commercially, and license their derivative works on different terms, provided the original work is properly cited, appropriate credit is given, any changes made indicated, and the use is non-commercial. See: http://creativecommons.org/licenses/by-nc/4.0/.

\section{REFERENCES}

1. Bruni O, Sullivan S, Guilleminault C. Pediatric sleep medicine: a key sub-specialty for the pediatrician. Sleep Med 2019.

2. Banasiak NC. Understanding the relationship between asthma and sleep in the pediatric population. J Pediatr Health Care 2016;30:546-50.

3. Hysing M, Sivertsen B, Stormark KM, et al. Sleep in children with chronic illness, and the relation to emotional and behavioral problems--a population-based study. J Pediatr Psychol 2009;34:665-70.

4. Wang B, Eastwood PR, Becker A, et al. Concurrent developmental course of sleep problems and Emotional/behavioral problems in childhood and adolescence as reflected by the dysregulation profile. Sleep 2018.

5. Ivanenko A, Crabtree VM, Obrien LM, et al. Sleep complaints and psychiatric symptoms in children evaluated at a pediatric mental health clinic. J Clin Sleep Med 2006;2:42-8.

6. Angriman M, Caravale B, Novelli L, et al. Sleep in children with neurodevelopmental disabilities. Neuropediatrics 2015;46:199-210.

7. Hansen BH, Oerbeck B, Skirbekk B, et al. Neurodevelopmental disorders: prevalence and comorbidity in children referred to mental health services. Nord J Psychiatry 2018;72:285-91.

8. Westbom L, Rimstedt A, Nordmark E. Assessments of pain in children and adolescents with cerebral palsy: a retrospective population-based registry study. Dev Med Child Neurol 2017;59:858-63.

9. Elgen SK, Leversen KT, Grundt JH, et al. Mental health at 5 years among children born extremely preterm: a national population-based study. Eur Child Adolesc Psychiatry 2012;21:583-9.

10. Stangenes KM, Fevang SK, Grundt J, et al. Children born extremely preterm had different sleeping habits at 11 years of age and more childhood sleep problems than term-born children. Acta Paediatr 2017;106:1966-72.

11. Fevang SKE, Hysing M, Sommerfelt K, et al. Mental health assessed by the Strengths and Difficulties Questionnaire for children born extremely preterm without severe disabilities at 11 years of age: a Norwegian, national population-based study. Eur Child Adolesc Psychiatry 2017;26:1523-31.

12. Baraldi E, Filippone M. Chronic lung disease after premature birth. $N$ Engl J Med 2007;357:1946-55.

13. Markestad T, Kaaresen PI, Rønnestad A, et al. Early death, morbidity, and need of treatment among extremely premature infants. Pediatrics 2005:115:1289-98.

14. Westby Wold SH, Sommerfelt K, Reigstad H, et al. Neonatal mortality and morbidity in extremely preterm small for gestational age infants: a population based study. Arch Dis Child Fetal Neonatal Ed 2009;94:F363-F367.

15. Leversen KT, Sommerfelt K, Rønnestad A, et al. Prediction of neurodevelopmental and sensory outcome at 5 years in Norwegian children born extremely preterm. Pediatrics 2011;127:e630-8.

16. Skromme K, Leversen KT, Eide GE, et al. Respiratory illness contributed significantly to morbidity in children born extremely premature or with extremely low birthweights in 1999-2000. Acta Paediatr 2015;104:1189-98.

17. Hirshkowitz M, Whiton K, Albert SM, et al. National sleep Foundation's updated sleep duration recommendations: final report. Sleep Health 2015;1:233-43.

18. Stangenes KM, Hysing M, Fevang SK, et al. Prenatal and neonatal factors predicting sleep problems in children born extremely preterm or with extremely low birthweight. Front Pediatr 2018;6.
19. Goodman R. The extended version of the strengths and difficulties questionnaire as a guide to child psychiatric caseness and consequent burden. J Child Psychol Psychiatry 1999;40:791-9.

20. Johnson S, Hollis C, Marlow N, et al. Screening for childhood mental health disorders using the strengths and difficulties questionnaire: the validity of multi-informant reports. Dev Med Child Neurol 2014;56:453-9.

21. ISAAC. International study of asthma and allergies in childhood) manual. 2nd Ed, 1993: 1-52.

22. Skjaerven R, Gjessing HK, Bakketeig LS. Birthweight by gestational age in Norway. Acta Obstet Gynecol Scand 2000;79:440-9.

23. Lødrup Carlsen KC, Håland G, Devulapalli CS, et al. Asthma in every fifth child in Oslo, Norway: a 10-year follow up of a birth cohort study. Allergy 2006;61:454-60.

24. Skromme K, Vollsæter M, Øymar K, et al. Respiratory morbidity through the first decade of life in a national cohort of children born extremely preterm. BMC Pediatr 2018;18:102.

25. Perkinson-Gloor N, Hagmann-von Arx P, Brand S, et al. The role of sleep and the hypothalamic-pituitary-adrenal axis for behavioral and emotional problems in very preterm children during middle childhood. J Psychiatr Res 2015;60:141-7.

26. Caravale B, Sette S, Cannoni E, et al. Sleep characteristics and temperament in preterm children at two years of age. J Clin Sleep Med 2017;13:1081-8.

27. Steinsbekk S, Wichstrøm L. Stability of sleep disorders from preschool to first grade and their bidirectional relationship with psychiatric symptoms. J Dev Behav Pediatr 2015;36:243-51.

28. Driouch J, Alfer D, Fricke-Oerkermann L, et al. Sleep problems, strengths and difficulties in elementary school children. Health 2013;05:87-94.

29. Hestetun I, Svendsen MV, Oellingrath IM. Sleep problems and mental health among young Norwegian adolescents. Nord $\mathrm{J}$ Psychiatry 2018;72:578-85.

30. Lee $\mathrm{CH}$, Kim YJ, Lee SB, et al. Psychological screening for the children with habitual snoring. Int J Pediatr Otorhinolaryngol 2014;78:2145-50.

31. Ross Kristie RS. Sleep Outcomes in Children Born Prematurly. In: Springer International Publishing, 2017: 161-79.

32. Emancipator JL, Storfer-Isser A, Taylor HG, et al. Variation of cognition and achievement with sleep-disordered breathing in full-term and preterm children. Arch Pediatr Adolesc Med 2006;160:203-10.

33. Biggs SN, Meltzer LJ, Tapia IE, et al. Sleep/Wake patterns and parental perceptions of sleep in children born preterm. J Clin Sleep Med 2016;12:711-7.

34. Rosen CL, Larkin EK, Kirchner HL, et al. Prevalence and risk factors for sleep-disordered breathing in 8- to 11-year-old children: association with race and prematurity. J Pediatr 2003;142:383-9.

35. Raynes-Greenow CH, Hadfield RM, Cistulli PA, et al. Sleep apnea in early childhood associated with preterm birth but not small for gestational age: a population-based record linkage study. Sleep 2012;35:1475-80.

36. Elisabeth Fosse $\mathrm{H}$, Fosse $\mathrm{H}$, Hysing M. Time in bed, sleep sufficiency and emotional and behavioral problems in a general population of 10-12 year old children. Open Sleep J 2011;4:29-35.

37. van Maanen A, Wijga AH, Gehring $U$, et al. Sleep in children with asthma: results of the PIAMA study. Eur Respir J 2013;41:832-7.

38. Chugh IM, Khanna P, Shah A. Nocturnal symptoms and sleep disturbances in clinically stable asthmatic children. Asian Pac $J$ Allergy Immunol 2006;24:135-42.

39. Jones CM, DeWalt DA, Huang I-C. Impaired patient-reported outcomes predict poor school functioning and daytime sleepiness: the PROMIS pediatric asthma study. Acad Pediatr 2017;17:850-4.

40. Filippone M, Carraro S, Baraldi E. The term "asthma" should be avoided in describing the chronic pulmonary disease of prematurity. Eur Respir J 2013;42:1430-1.

41. Halvorsen T, Skadberg BT, Eide GE, et al. Characteristics of asthma and airway hyper-responsiveness after premature birth. Pediatr Allergy Immunol 2005;16:487-94.

42. Filippone M, Bonetto $\mathrm{G}$, Corradi M, et al. Evidence of unexpected oxidative stress in airways of adolescents born very pre-term. Eur Respir J 2012;40:1253-9.

43. Bub KL, Buckhalt JA, El-Sheikh M. Children's sleep and cognitive performance: a cross-domain analysis of change over time. Dev Psychol 2011;47:1504-14.

44. Buck GM, Msall ME, Schisterman EF, et al. Extreme prematurity and school outcomes. Paediatr Perinat Epidemiol 2000;14:324-31.

45. Diette GB, Markson L, Skinner EA, et al. Nocturnal asthma in children affects school attendance, school performance, and parents' work attendance. Arch Pediatr Adolesc Med 2000;154:923-8. 